\title{
Pressure drop in a packed bed with sintered ore particles as applied to sinter coolers with a novel vertically arranged design for waste heat recovery"
}

\author{
Fu-you TIAN ${ }^{1}$, Lian-feng HUANG ${ }^{1}$, Li-wu FAN ${ }^{\dagger 1,2}$, Hong-liang QIAN $^{1}$, Jia-xi GU ${ }^{1}$, \\ Zi-tao $\mathrm{YU}^{1,3}$, Ya-cai $\mathrm{HU}^{1}$, Jian $\mathrm{GE}^{4}$, Ke-fa $\mathrm{CEN}^{2}$ \\ ('Institute of Thermal Science and Power Systems, School of Energy Engineering, Zhejiang University, Hangzhou 310027, China) \\ ( ${ }^{2}$ State Key Laboratory of Clean Energy Utilization, Zhejiang University, Hangzhou 310027, China) \\ $\left({ }^{3}\right.$ Key Laboratory of Refrigeration and Cryogenic Technology of Zhejiang Province, Zhejiang University, Hangzhou 310027, China) \\ ( ${ }^{4}$ Institute of Architectural Technologies, School of Civil Engineering and Architecture, Zhejiang University, Hangzhou 310058, China) \\ †E-mail: liwufan@zju.edu.cn \\ Received Apr. 14, 2015; Revision accepted Aug. 10, 2015; Crosschecked Jan. 16, 2016
}

\begin{abstract}
The pressure drop over a packed bed with sintered ore particles was studied experimentally. The sintered ore particles were characterized to determine their equivalent particle diameter, bed voidage, and sphericity. The pressure drop experiments were performed on unsorted and sieved particles with various size distributions for a superficial velocity up to $2.4 \mathrm{~m} / \mathrm{s}$, covering flow regimes from laminar to turbulent. It was shown that the Ergun equation underestimates the pressure drop for such highly irregular-shaped particles by about $40 \%$. The measured modified friction factor was well correlated to a scaled Ergun equation, which was verified to be valid for the modified particle Reynolds number up to 12000 toward design and optimization of vertically arranged sinter coolers for waste heat recovery.
\end{abstract}

Key words: Pressure drop, Porous media, Sinter cooler, Sintered ore particle, Waste heat recovery http://dx.doi.org/10.1631/jzus.A1500088

CLC number: TK172

\section{Introduction}

The iron and steel industry is one of the largest energy-consuming industries, accounting for $5.2 \%$ of the total energy consumed in the entire manufacturing sector in the USA (Worrell et al., 2010), while being as high as $25 \%$ in China (Yang, 2014). Among vari-

\footnotetext{
${ }^{\ddagger}$ Corresponding author

" Project supported by the National Natural Science Foundation of China (No. 51378482), the Scientific Research Foundation for the Returned Overseas Chinese Scholars, Ministry of Education of China, and the Foundation of Zhejiang CWPC \& BR Heavy Industry Co., Ltd., China

(b) ORCID: Fu-you TIAN, http://orcid.org/0000-0001-9701-5919; Li-wu FAN, http://orcid.org/0000-0001-8845-5058

(C) Zhejiang University and Springer-Verlag Berlin Heidelberg 2016
}

ous procedures adopted during ironmaking and steelmaking ( $\mathrm{Li}$ and $\mathrm{Wu}, 2007)$, sintering is responsible for $7 \%-15 \%$ of the total energy consumption, according to the statistical data for both USA and China (Worrell et al., 2010; Wu et al., 2012; Yang, 2014). Recovery of the sensible heat of the cooling air from sinter coolers has been identified, by the European Commission for instance (Pardo et al., 2012), as one of the promising approaches to energy efficiency improvement for the iron and steel industry.

Hot sintered ore particles (SOPs) from the sinter machines are commonly cooled in belt- or circulartype sinter coolers. Due to the undesirably high air leakage, however, the efficiency of waste heat recovery by these two types of sinter coolers is significantly limited. A novel design of sinter coolers 
featuring a vertical arrangement, resembling the coke dry quenching operation in vertical tanks, has been proposed in an effort to improve the waste heat recovery efficiency (Zhao et al., 2009), by taking advantage of the reduced air leakage in the more compact vertical tanks and more efficient heat transfer via countercurrent flow arrangement between the cooling air blowing upward and the SOPs that slowly drop down (Dong et al., 2012b). To better understand and optimize the operation of vertically arranged sinter coolers, issues regarding packing voidage (Zhang et al., 2012), pressure drop (Feng et al., 2014), and heat transfer (Dong and Li, 2011; Dong et al., 2012a; 2014; Huang et al., 2015 ) have recently been addressed in available literature, with the packed layers of SOPs being treated as stationary packed beds for simplification, considering the low descending velocity (about $1 \times 10^{-3} \mathrm{~m} / \mathrm{s}$ ) of the SOPs in the vertical tanks (Feng et al., 2014).

The knowledge of pressure drop over the packed layers/beds of SOPs is deemed essential for the analysis and optimization of sinter coolers, because it is not only directly related to the blowing costs but also has significant impact on the overall heat transfer performance. The pressure drop data/correlations for packed layers of SOPs, however, have not yet been well documented in available literature. The widely adopted Ergun equation, relating the pressure drop over a packed bed in terms of the Reynolds ( $R e$ ) number (Ergun, 1952), has been used in a number of numerical efforts to study flow and heat transfer in circular-type sinter coolers (Tadayuki et al., 1990; Caputo and Pelagagge, 2001; Leong et al., 2009; Zhang et al., 2013; Liu et al., 2014). In the absence of experimental verification, it seems questionable to directly apply the Ergun equation for predicting the pressure drop over a packed bed with highly irregular-shaped SOPs, because the original Ergun equation is valid for spherical particles (Mayerhofer et al., 2011). In fact, it has been shown that the Ergun equation underestimates significantly the pressure drop of packed beds with other irregular-shaped wood particles (Shitzer and Levy, 1983) and rocks (MacDonald et al., 1979; Allen et al., 2013) for bioenergy conversion and solar thermal energy storage applications, respectively. In addition, typical Re numbers encountered in sinter coolers are far beyond the applicable range of the Ergun equation, which was proposed for relatively low flow rates, leading to additional discrepancies for the pressure drop predictions. Although modified Ergun equations have been proposed with empirically determined constants for particular conditions of interest (Nemec and Levec, 2005), verified, particular correlations for the pressure drop over packed layers/beds of SOPs are lacking thus far.

To extend the existing knowledge, the pressure drop over a packed bed with irregularly shaped SOPs will be measured experimentally, with an emphasis on the effects of particle shape and size distribution. An examination of the pressure drop in the same packed bed with spherical particles will be performed as a baseline case for comparison. Correlations based on the modified Ergun equation will be proposed to predict the pressure drop over the SOP-filled packed bed as applied to vertically arranged sinter coolers.

\section{Experimental}

\subsection{Characterization of the SOPs}

In this study, SOP samples were provided by the Hangzhou Iron and Steel Group Company, China. The samples were porous and irregularly shaped over a wide range of sizes. The size distribution of the samples was determined by the sieving method. The samples for each 10-mm size range were weighed after sieving to calculate their mass fraction. As shown in Fig. 1, the measured size distribution is consistent among the four different batches. The samples having a size within the range of 10-60 mm occupy a large proportion (about $80 \%$ ) of the total mass. All pressure drop experiments were conducted for unsorted and sieved samples within this representative range, as demonstrated in Fig. 2, in which the porous structures and irregular shapes are clearly seen.

The apparent density $\rho_{\mathrm{a}}$ of the SOPs was measured by the displacement method with water using 20 randomly selected samples of known masses, while the bulk density $\rho_{\mathrm{b}}$ was directly measured in a packed bed of known volume. With the knowledge of the densities, the voidage of the packed bed $\varepsilon$ was found using the following definition:

$$
\varepsilon=1-\frac{\rho_{\mathrm{b}}}{\rho_{\mathrm{a}}},
$$

and the equivalent spherical volume diameter $d_{\mathrm{s}}$ of an individual SOP sample was calculated by 


$$
d_{\mathrm{s}}=\left(\frac{6 m_{\mathrm{p}}}{\pi \rho_{\mathrm{a}}}\right)^{1 / 3},
$$

where $m_{\mathrm{p}}$ is the mass of the sample. By individually weighing a statistically large number $(>200)$ of SOP samples in each of the $10-\mathrm{mm}$ size range, from $10 \mathrm{~mm}$ to $60 \mathrm{~mm}$, the respective average equivalent spherical volume diameter was determined.

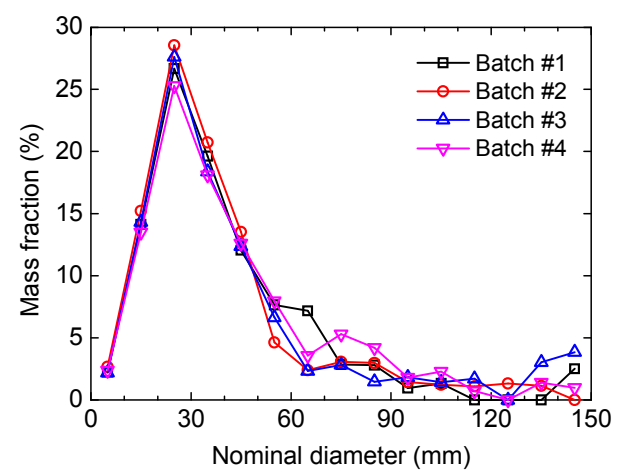

Fig. 1 Measured size distribution by mass fraction of the SOP samples

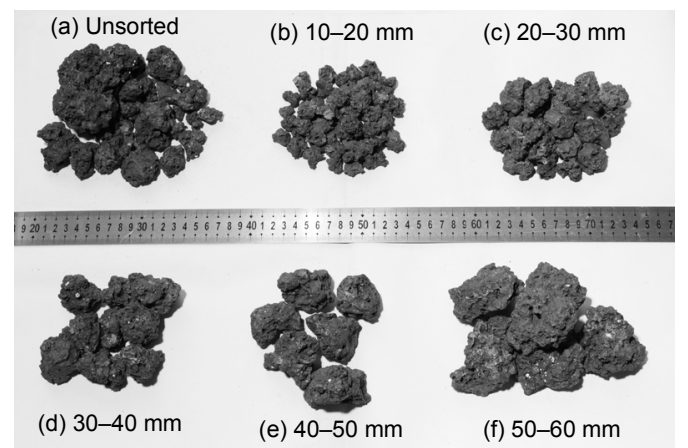

Fig. 2 Photographs taken on the unsorted (a) and the sieved SOP samples having a nominal diameter within the ranges of 10-20 mm (b), $20-30 \mathrm{~mm}$ (c), 30-40 mm (d), 40-50 $\mathrm{mm}(\mathrm{e})$, and 50-60 $\mathrm{mm}(\mathrm{f})$

The equivalent particle diameter $d_{\mathrm{p}}$ was evaluated using the following definition:

$$
d_{\mathrm{p}}=\frac{6 V_{\mathrm{p}}}{S_{\mathrm{p}}}
$$

where $V_{\mathrm{p}}$ and $S_{\mathrm{p}}$ stand for the volume and surface area of the particle, respectively. The volume and surface area of an individual SOP sample were measured by reconstructing its 3D geometry on a MaxSHOT 3D optical coordinate measuring system. A typical SOP sample and its reconstructed image are shown in Fig. 3. Comparing the measured volumes by this optical method to those determined by the displacement method, a good agreement was found, with discrepancies being $<6 \%$, thus indicating that the portion of through holes on the SOP samples is negligible although they look porous. As can be seen from Fig. 3, uncertainty exists for the surface area determination as the rough, porous surface was somewhat smoothed by the scanning algorithm. The average equivalent particle diameter for a certain size range of interest was calculated over 60 samples. In addition, the sphericity $\phi$ of an individual SOP sample was evaluated by

$$
\phi=\frac{d_{\mathrm{p}}}{d_{\mathrm{s}}} .
$$
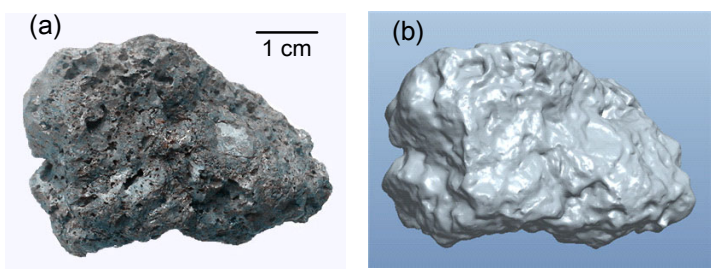

Fig. 3 A typical SOP sample: (a) a photograph; (b) the 3D image reconstructed by the optical method

As mentioned, commercially available glass beads were tested as reference spherical particles for comparison. Three nominal monodisperse diameters of the glass beads, i.e., 16,25 , and $35 \mathrm{~mm}$, were chosen to represent the size ranges of 10-20, 20-30, and 30-40 mm, respectively. The diameter of an individual glass bead was measured by means of a digital caliper, with the density being readily obtained after weighing.

\subsection{Packed bed test setup and procedure}

A cold test setup was designed and constructed, as illustrated in Fig. 4, for measuring the pressure drop over a packed bed of SOPs, with its size being scaled down from the industrial prototypes of vertically arranged sinter coolers having a diameter of $>5 \mathrm{~m}$. In the present setup, the test section was composed of a cylindrical Plexiglas ${ }^{\circledR}$ tube of height $H=500 \mathrm{~mm}$, which was vertically positioned. The inner diameter 
$D$ of the tube was $270 \mathrm{~mm}$, which was comparable to those adopted by Zhang et al. (2012) in their study to measure the packing voidage of SOPs.

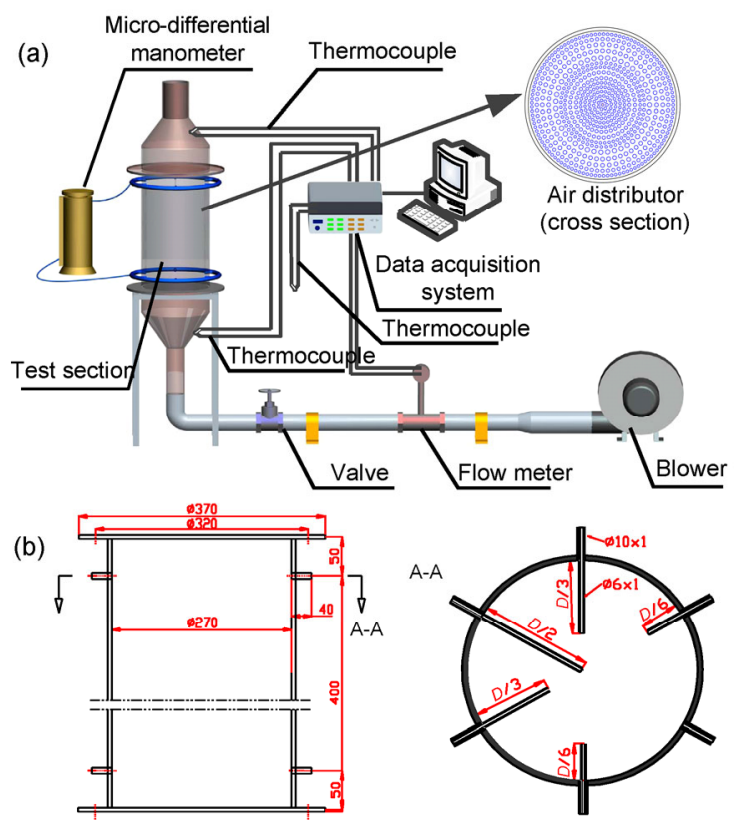

Fig. 4 Packed bed test setup: (a) a schematic diagram; (b) a drawing of the test section with dimensions (unit: $\mathbf{m m}$ )

In consistency with the operation of vertically arranged sinter coolers, air was blown upward to enter the test section from its bottom. The volumetric airflow rate $Q$ was monitored by a vortex flow meter having an applicable range of $100-600 \mathrm{~m}^{3} / \mathrm{h}$. The piping layout including the reducer pipe is clearly shown in Fig. 4. A perforated plate made of stainless steel was used as both the support for the test section and an air distributor. Through the arrayed holes $(5-8 \mathrm{~mm}$ in diameter, area of the holes occupying about $30 \%$ of the overall cross section) on this plate, the airflow was regulated to be more uniformly distributed before entering the test section. The pressure drop $\triangle P$ over the packed layer of distance $L=400 \mathrm{~mm}$ (Fig. 4) was measured using a microdifferential manometer (up to $2500 \mathrm{~Pa}$ ) and a digital micro-manometer (up to $6000 \mathrm{~Pa}$ ). At each level of interest, six equally distributed pressure probes were mounted radially. As clearly shown in Fig. 4, the insertion depths of the probes were varied so that the reading of the manometer represents the averaged pressure drop value over the cross section at that level. The pressure drop was found to be stable, with maximum fluctuation of only $1 \%$, even in the turbulent regime. Moreover, thermocouples were mounted at several places to ensure that all experiments were carried out at nearly isothermal conditions in an airconditioned room. The flow meter and thermocouple readings were logged at a frequency of $0.1 \mathrm{~Hz}$ by the data acquisition system, whereas the pressure drop data were recorded manually every $20 \mathrm{~s}$.

The packing was done by slowly feeding the SOP or glass bead samples of desirable sizes into the test section in a layer-by-layer approach. After feeding each layer to a height of about $50 \mathrm{~mm}$, the packed particles were subjected to gentle shock and compaction to ensure a firm bed. This procedure was rigorously followed in all experiments. However, the randomly distributed nature of the packed layer of irregularly shaped SOPs led to unavoidable spreading of the data. Hence, parallel tests were performed three times for each case to ensure data reproducibility.

\section{Data reduction}

As mentioned, the airflow rate $Q$ and pressure drop $\Delta P$ were the two major parameters of interest that were directly measured by the packed bed test setup. The superficial velocity $U$ through the test section was evaluated using the known flow rate as

$$
U=\frac{4 Q}{\pi D^{2}} .
$$

Based on the equivalent particle diameter, the particle $R e$ number is defined by

$$
\operatorname{Re}=\frac{\rho U d_{\mathrm{p}}}{\mu}
$$

where $\rho$ and $\mu$ are the density and viscosity of air, respectively, at room temperature. Moreover, the modified $R e$ number for a packed bed with a voidage $\varepsilon$ may be defined by

$$
R e_{\mathrm{m}}=\frac{R e}{1-\varepsilon}=\frac{\rho U d_{\mathrm{p}}}{\mu(1-\varepsilon)} .
$$

Establishment of the relationships between the pressure drop over a packed bed and its superficial velocity (or modified $R e$ number) has been a major 
task in the literature, which was also the primary objective of the present work for SOPs.

\subsection{Pressure drop over packed beds}

In practice, the flow pattern in vertically arranged sinter coolers is likely in the non-Darcy regime as the flow velocity through the packed beds is of the order of $1 \mathrm{~m} / \mathrm{s}$. The pressure drop per unit length of non-Darcy flows may be determined by the Forchheimer equation (Fand et al., 1987):

$$
\frac{\Delta P}{L}=\frac{\mu}{K} U+\frac{\rho F}{K^{0.5}} U^{2},
$$

where $K$ is the permeability, and $F$ is the form-andinertial drag coefficient, also known as the Forchheimer coefficient. The first and second terms on the right hand side of Eq. (8) represent the viscous and inertial contributions to pressure drop, respectively.

A slightly modified form of Eq. (8) can be obtained by dividing both sides by the superficial velocity (Dukhan et al., 2014), which is expressed as

$$
\frac{\Delta P}{L U}=\frac{\mu}{K}+\frac{\rho F}{K^{0.5}} U
$$

Plotting the reduced pressure drop $\Delta P /(L U)$ vs. superficial velocity $U$ of different packed beds can clearly show the variations of the macroscopic parameters $K$ and $F$. However, a major shortcoming of such Forchheimer-type equation is that the properties of a packed bed voidage for instance are not explicitly taken into account (Fand et al., 1987).

By considering the voidage of a packed bed and the particle diameter, the following Ergun equation was thus proposed (Ergun, 1952):

$$
\frac{\Delta P}{L}=A \frac{\mu(1-\varepsilon)^{2}}{d_{\mathrm{p}}^{2} \varepsilon^{3}} U+B \frac{\rho(1-\varepsilon)}{d_{\mathrm{p}} \varepsilon^{3}} U^{2},
$$

where $A$ and $B$ are the viscous constant (often referred to as Blake-Kozeny-Carman constant) and the inertial constant (Burke-Plummer constant), respectively.

The pressure drop may be written in the form of a dimensionless friction factor as

$$
f=\frac{\Delta P}{L} \frac{d_{\mathrm{p}}^{2}}{\mu U}
$$

and its modified form for a packed bed may be defined by

$$
f_{\mathrm{m}}=\frac{\Delta P}{L} \frac{d_{\mathrm{p}}^{2}}{\mu U} \frac{\varepsilon^{3}}{(1-\varepsilon)^{2}}
$$

Hence, the Ergun equation, Eq. (10), can be reduced to a linear form as

$$
f_{\mathrm{m}}=A+B R e_{\mathrm{m}} .
$$

The values for the empirical constants $A$ and $B$ are 150 and 0.75 , as suggested by Ergun (1952). As listed in Table 1, a variety of combinations of $A$ and $B$ values have been proposed depending on the ranges of the particle diameter, bed voidage, and modified $R e$ number. The bed-to-particle ratio $D / d_{\mathrm{p}}$ is also listed for reference. The wall effect exerted on the flow through packed beds tends to be less significant when this ratio becomes larger.

As argued by Montillet (2004), the pressure drop over a finite packed bed is not proportional to the square of the flow velocity. Therefore, the following modified equation was proposed:

$$
f_{\mathrm{m}}=A+B R e_{\mathrm{m}}^{n},
$$

with an additional scaling exponent $n$ for the modified $R e$ number. This scaled equation has been shown to give rise to better fitting for the data over a wider range of the modified Re number. Several combinations of $A, B$, and $n$ proposed in available literature are listed in Table 2.

\subsection{Flow pattern in packed beds}

The pressure drop over packed beds is greatly affected by the flow pattern. With increase in the Re number, a non-Darcy flow pattern may be subjected to transitions from the inertial flow regime (also known as steady nonlinear laminar flow regime), to the unsteady laminar flow regime (transition flow regime), and finally to the turbulent flow regime (Dybbs and Edwards, 1984). Identification of the flow regimes has been attempted by various approaches. In theory, flow visualization (Dybbs and Edwards, 1984) and current fluctuation measurement (Seguin et al., 1998) are direct methods that provide definitive evidence on the 
Table 1 Empirical values for constants $A$ and $B$ in the expression $f_{\mathrm{m}}=A+B R e_{\mathrm{m}}$

\begin{tabular}{lcccccc}
\hline \multicolumn{1}{c}{ Source } & $A$ & $B$ & $d_{\mathrm{p}}(\mathrm{mm})$ & $\varepsilon$ & $R e_{\mathrm{m}}$ & $D / d_{\mathrm{p}}$ \\
\hline Ergun (1952) & 150 & 1.75 & $0.497-12.7$ & $0.260-0.764$ & $0-10^{3}$ & N/A \\
MacDonald et al. (1979) & 180 & $1.8-4.0$ & $8 \times 10^{-3}-109.7$ & $0.123-0.919$ & $10^{-3}-10^{4}$ & N/A \\
Handley and Heggs (1968) & 368 & 1.24 & $31.7,95.2$ & 0.390 & $654-6533$ & $8-24$ \\
\hline
\end{tabular}

Table 2 Empirical values for constants $A, B$, and $\boldsymbol{n}$ in the expression $f_{\mathrm{m}}=A+B R e_{\mathrm{m}}{ }^{n}$

\begin{tabular}{lccccccc}
\hline \multicolumn{1}{c}{ Source } & $A$ & $B$ & $n$ & $d_{\mathrm{p}}(\mathrm{mm})$ & $\varepsilon$ & $R e_{\mathrm{m}}$ & $D / d_{\mathrm{p}}$ \\
\hline Carman (1937) & 180 & 2.87 & 0.90 & $0.25-50$ & $0.286-0.90$ & $0.1-6 \times 10^{4}$ & N/A \\
Tallmadge (1970) & 150 & 4.20 & 0.83 & 31.24 & $0.35-0.88$ & $0.1-10^{5}$ & $5-35$ \\
Jones and Krier (1983) & 150 & 3.89 & 0.87 & $0.96-6$ & $0.38-0.43$ & $733-126670$ & $8.5-53$ \\
\hline
\end{tabular}

existence of the flow regimes under investigation. A pressure-based, indirect method, however, has been adopted for flow regime identification due to its simplicity and convenience (Kececioglu and Jiang, 1994; Seguin et al., 1998). The principle of this method is to calculate the ratio of the inertial contribution to the total pressure drop. Based on the Forchheimer equation, Eq. (8), the ratio $X$ may be found by

$$
X=1-\frac{\mu U}{K} \frac{L}{\Delta P}
$$

The flow regimes through the packed bed of SOPs were able to be identified through variations of this ratio. As concluded by Seguin et al. (1998), the inertial contribution represents approximately $70 \%$ and $91 \%$ of the total pressure drop at the onset of transition and turbulent regimes, respectively. These two threshold values were used as the criteria for flow regime identification in this study.

\subsection{Experimental uncertainty analysis}

The uncertainties in the pressure drop experiments primarily stem from the measurement errors of flow velocity and pressure drop, as well as from the properties of SOPs. Experimental uncertainties of several original quantities of interest are as follows. The accuracy of the vortex flow meter was calibrated to be $1 \%$, while the microdifferential manometer and the digital micro-manometer had uncertainties up to $1.3 \mathrm{~Pa}$ and $50 \mathrm{~Pa}$ for the range of $0-2500 \mathrm{~Pa}$ and 2500-6000 Pa, respectively. The uncertainties of the dimension measurements were $\pm 0.5 \mathrm{~mm}$ and $\pm 0.02 \mathrm{~mm}$ for the test section and glass bead samples, respectively. The uncertainties associated with the reduced quantities were evaluated via the error propagation theory. As an example, the uncertainty for the particle $R e$ number was quantified using the expression:

$$
\frac{\delta R e}{\operatorname{Re}}=\left[\left(\frac{\delta \rho}{\rho}\right)^{2}+\left(\frac{\delta U}{U}\right)^{2}+\left(\frac{\delta d_{\mathrm{p}}}{d_{\mathrm{p}}}\right)^{2}+\left(\frac{\delta \mu}{\mu}\right)^{2}\right]^{1 / 2}
$$

where the symbol $\delta$ in front of various quantities denotes the absolute measurement errors for them. As listed in Table 3, the uncertainties for all the reduced quantities were evaluated in a similar way, except for those associated with the geometric properties of the SOPs, which were determined from parallel tests on multiple samples.

Table 3 Experimental uncertainties of the reduced quantities of interest

\begin{tabular}{lr}
\hline \multicolumn{1}{c}{ Property/Parameter } & $\begin{array}{c}\text { Uncertainty } \\
(\%)\end{array}$ \\
\hline Packed bed voidage, $\varepsilon$ & 1.66 \\
Equivalent particle diameter, $d_{\mathrm{p}}(\mathrm{mm})$ & 4.06 \\
Sphericity, $\phi$ & 10.60 \\
Superficial velocity, $U(\mathrm{~m} / \mathrm{s})$ & 1.03 \\
Particle $R e$ number, $R e$ & 5.15 \\
Modified $R e$ number, $R e_{\mathrm{m}}$ & 5.97 \\
Pressure drop per unit length, $\Delta P / L(\mathrm{~Pa} / \mathrm{m})$ & 6.49 \\
Reduced pressure drop, $\Delta P /(L U)\left(\mathrm{Pa} \cdot \mathrm{s} / \mathrm{m}^{2}\right)$ & 7.48 \\
Modified friction factor, $f_{\mathrm{m}}$ & 16.45 \\
Ratio of inertial contribution, $X$ & 7.50 \\
\hline
\end{tabular}

\section{Results and discussion}

As mentioned, pressure drop experiments were performed for the packed bed with SOPs or glass 
beads of various sizes. The measured data for SOPs were reduced to come up with appropriate pressure drop correlations with application to vertically arranged sinter coolers.

\subsection{Geometric properties of the SOPs}

Prior to pressure drop experiments, the SOP and glass bead samples were subjected to a variety of characterizations for their geometric properties, including the equivalent particle diameter, bed voidage, sphericity, and bed-to-particle diameter ratio. The measured properties of the SOP samples for various size ranges are summarized in Table 4. For each size range, the equivalent particle diameter is close to or even becomes much smaller than the lower limit. It is understood to be related to the principle of the sieving method for such highly irregularly shaped particles. The average equivalent particle diameter for the unsorted SOP samples is $17.13 \mathrm{~mm}$, which is consistent with the size distribution by mass fraction (Fig. 1).

The bed voidage is about 0.6 for all the cases, which is slightly increased when the particle size becomes larger, suggesting that smaller SOPs tend to be more densely packed. The bed voidage for the unsorted case is almost identical to that for the size range of $30-40 \mathrm{~mm}$, corresponding to an average equivalent particle diameter of $18.60 \mathrm{~mm}$. Note that the bed voidage in this study is greater than the value of about 0.4 reported by Zhang et al. (2012), although packed beds with comparable diameter and height and SOPs with similar sizes were adopted. The irregular shape of the SOPs is confirmed by the measured sphericity ranging from 0.62 to 0.66 . In contrast, the measured properties of the glass beads are listed in Table 5. The actual diameters of the beads are slightly different from the corresponding nominal values. The spherical particles were able to be packed more densely than the irregularly shaped SOPs, with the bed voidage being about 0.4 .
As discussed before, the bed-to-particle diameter ratio is directly related to the wall effect. As suggested by Nemec and Levec (2005), the wall effect should be considered when $D / d_{\mathrm{p}}<10$. As listed in Table 5 , the ratio was determined to range from 7 to 27 for both SOPs and glass beads, indicating that the wall effect may be neglected in the measured pressure drop despite the lack of quantitative analysis. Moreover, the present ratio range is in accordance with the applicable range of various empirical equations, as listed in Tables 1 and 2.

Table 5 Measured geometric properties of the glass beads

\begin{tabular}{ccccc}
\hline Size $(\mathrm{mm})$ & $d_{\mathrm{p}}(\mathrm{mm})$ & $\varepsilon$ & $\phi$ & $D / d_{\mathrm{p}}$ \\
\hline 16 & 16.13 & 0.386 & 1 & 16.74 \\
25 & 24.72 & 0.402 & 1 & 10.92 \\
35 & 34.50 & 0.425 & 1 & 7.82 \\
\hline
\end{tabular}

\subsection{Comparison to existing correlations}

A packed bed with three sizes of glass beads was first tested to validate the present setup. As plotted in Fig. 5, the measured modified friction factors associated with various glass beads almost collapse on a single curve for the modified Re number up to $9 \times 10^{3}$. This suggests that the measured friction factor is almost independent of the sphere diameter within the range tested. Comparison of the measured data to predictions by existing correlations is shown in Fig. 5, where the Ergun equation (Ergun, 1952) of the linear form (Table 1) and the Carman equation (Carman, 1937) of the scaled form (Table 2) were chosen. The linear trend predicted by the Ergun equation overestimates the measured variation of the friction factor. The discrepancy becomes more pronounced with increase in the modified $R e$ number, although good agreement is seen for $R e_{\mathrm{m}}<1000$, which is also the applicable range of the original Ergun equation. In contrast, the curve predicted by the scaled equation is

Table 4 Measured geometric properties of the SOP samples

\begin{tabular}{ccccc}
\hline Size $(\mathrm{mm})$ & $d_{\mathrm{p}}(\mathrm{mm})$ & $\varepsilon$ & $\phi$ & $D / d_{\mathrm{p}}$ \\
\hline $10-20$ & $10.08 \pm 1.39$ & $0.557 \pm 0.003$ & $0.6542 \pm 0.0571$ & 26.79 \\
$20-30$ & $13.89 \pm 1.60$ & $0.574 \pm 0.007$ & $0.6410 \pm 0.0382$ & 19.44 \\
$30-40$ & $18.60 \pm 2.51$ & $0.578 \pm 0.006$ & $0.6235 \pm 0.0661$ & 14.52 \\
$40-50$ & $24.04 \pm 3.47$ & $0.607 \pm 0.005$ & $0.6204 \pm 0.0553$ & 11.23 \\
$50-60$ & $30.78 \pm 3.30$ & $0.616 \pm 0.003$ & $0.6548 \pm 0.0498$ & 8.77 \\
Unsorted & $17.13 \pm 6.39$ & $0.579 \pm 0.010$ & $0.6322 \pm 0.0574$ & 15.76 \\
\hline
\end{tabular}


in fairly good agreement with the measured data for the entire range of Re numbers. Having shown the agreements, confidence has been established for the present test setup to measure the pressure drop over a packed bed.

Comparison between the measured data of the SOPs and glass beads of comparable sizes was also made. SOPs within a size range of $40-50 \mathrm{~mm}$ and $25-\mathrm{mm}$ glass beads were chosen as they possess nearly identical equivalent particle diameters. As shown in Fig. 6, the pressure drop per unit length over the packed bed with SOPs is greater by a factor of $60 \%$ than that for the case with glass beads, as a result of the looser packing of the irregularly shaped SOPs. Unlike the comparison for the case of glass beads, both Ergun and Carman equations fail in the presence of SOPs, with the underestimation of the predicted curves being nearly $50 \%$ against the measured one. This indicates that the packing voidage and pressure drop of a packed bed are greatly affected by the

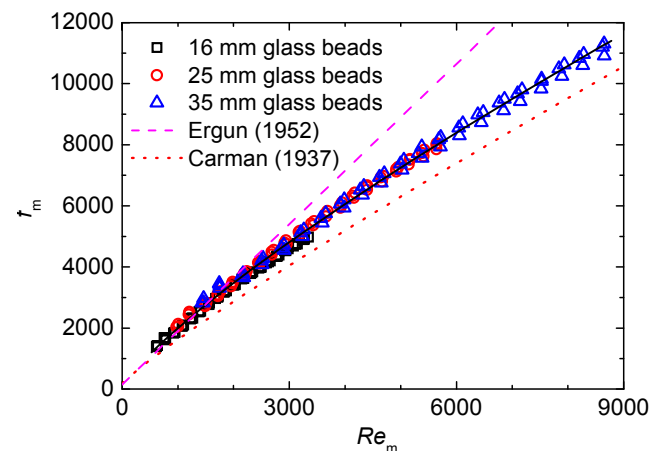

Fig. 5 Measured modified friction factor as a function of the modified $R e$ number for the packed bed with glass beads (the variations predicted by available empirical equations, proposed by Ergun (1952) and Carman (1937), are given for comparison)

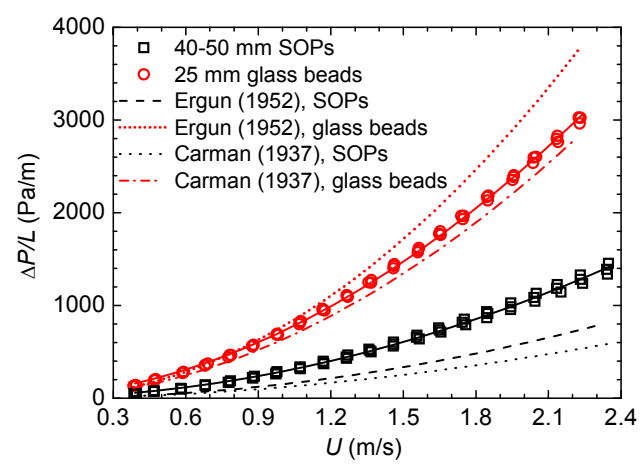

Fig. 6 Comparison between the measured and predicted pressure drops as functions of the superficial velocity for the packed bed with SOPs or glass beads particle shape. Obviously, the existing empirical equations may not be directly applicable to the case of irregularly shaped SOPs, emphasizing again the significance of developing pressure drop correlations for the particular condition of SOPs.

\subsection{Macroscopic packed bed parameters}

The variations of the reduced pressure drop per unit length as a function of the superficial velocity are presented in Fig. 7 for various size ranges of SOPs. Good reproducibility is seen by the consistency among the three sets of data for each case. As expected, the pressure drop becomes greater with decrease in the particle size (and the bed voidage). The data points for the unsorted case are close to those for the size range of $30-40 \mathrm{~mm}$, in consistency with the nearly identical bed voidage values of these two cases.

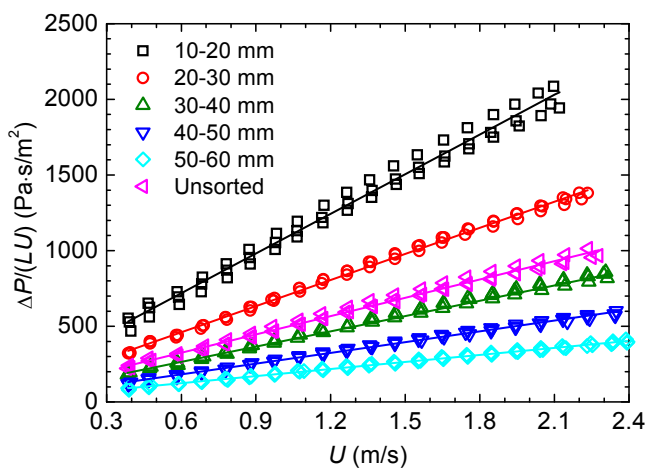

Fig. 7 Measured reduced pressure drop as a function of the superficial velocity for the packed bed with SOPs of various sizes

A linearly increasing trend of the pressure drop is also found with increase in the superficial velocity. The linear fit curves of various cases are also presented. According to the modified Forchheimer equation, Eq. (9), the permeability $K$ and Forchheimer coefficient $F$ for the packed bed with the various sizes of SOPs were readily obtained, as listed in Table 6. The data for the three sizes of glass beads are given for comparison. The permeability of the packed bed increases with increase in the particle size. It is understood that larger particles tend to form wider pores and/or channels between neighboring particles. At similar equivalent particle diameter, the permeability for SOPs is two to three times greater than that for glass beads, in accordance with the pressure drop contrast presented in Fig. 6. As indicated by the definition 
of sphericity, Eq. (4), the equivalent spherical volume diameter of the irregularly shaped SOPs is much greater than that for the spherical glass beads, thus leading to higher permeability through the larger pores/channels within the less densely packed SOPs.

In contrast to the permeability, the Forchheimer coefficient becomes lower with increase in the particle size, indicating that the drag effect tends to be less significant for larger particles. The particle shape effect may be negligible on this drag coefficient as good agreement is found between the coefficients for SOPs and glass beads with similar sizes. The drag coefficient is strongly affected by microscale mechanisms, such as surface roughness of the particles, which were not taken into consideration in this study focusing on the macroscopic behaviors.

Table 6 Macroscopic parameters of the packed bed with the various SOP or glass bead samples

\begin{tabular}{ccccc}
\hline Particle & Size $(\mathrm{mm})$ & $K\left(\times 10^{-8} \mathrm{~m}^{2}\right)$ & $F$ & $R^{2^{*}}$ \\
\hline \multirow{6}{*}{ SOP } & $10-20$ & 9.7 & 0.24 & 0.9861 \\
& $20-30$ & 16.1 & 0.20 & 0.9969 \\
& $30-40$ & 29.4 & 0.16 & 0.9945 \\
& $40-50$ & 47.0 & 0.14 & 0.9956 \\
& $50-60$ & 59.6 & 0.10 & 0.9958 \\
& Unsorted & 22.4 & 0.16 & 0.9924 \\
\hline \multirow{2}{*}{ Glass } & 16 & 6.0 & 0.19 & 0.9972 \\
bead & 25 & 11.5 & 0.14 & 0.9969 \\
& 35 & 20.2 & 0.10 & 0.9954 \\
\hline
\end{tabular}

${ }^{*} R^{2}$ is the coefficient of determination

\subsection{Flow regime identification}

After determining the permeability, the ratio of inertial contribution to the total pressure drop was readily obtained by Eq. (15). The variations of this ratio as functions of the superficial velocity are presented in Fig. 8 for the various SOPs and glass beads. The two horizontal lines at $X=0.7$ and 0.91 are given as the critical thresholds for flow regime identification (Seguin et al., 1998). At a constant superficial velocity, the ratio spreads to some extent for the SOPs with various sizes, with the deviation converging with increasing velocity. The ratio for the glass beads is, however, almost independent of the size within the range tested.

In general, laminar flow regime is only achieved for superficial velocity $<0.7 \mathrm{~m} / \mathrm{s}$ for the SOP-filled packed bed. Mostly, the flow pattern lies in the transition flow regime, as shown in Fig. 8. As the superficial velocity increases to $>2.1 \mathrm{~m} / \mathrm{s}$, the flow becomes turbulent for all the size ranges of SOPs, which is consistent with the value of $2.3 \mathrm{~m} / \mathrm{s}$ reported by Feng et al. (2014). The turbulent flow regime is, however, absent for the packed bed with glass beads for the superficial velocity up to $2.4 \mathrm{~m} / \mathrm{s}$. The critical velocity for the transition flow regime is about $1.0 \mathrm{~m} / \mathrm{s}$, which is also greater than that for the packed bed with SOPs, suggesting that the flow in the glass bead-filled bed with more organized, patterned pores/channels is more stable than that in SOP-filled bed. Due to the randomly distributed nature, the flow pattern in the packed bed with SOPs is highly localized. The identification of flow regimes by the pressure drop method is only able to provide a rough, macroscopic estimation.

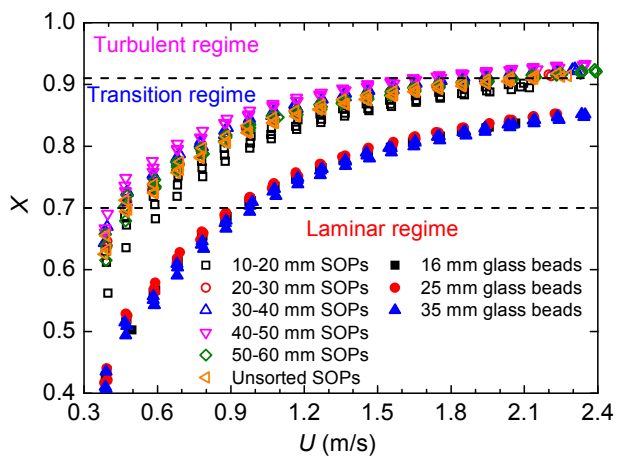

Fig. 8 Ratio of inertial contribution to the total pressure drop as a function of the superficial velocity (the threshold curves for flow regime identification are plotted for reference)

\subsection{Pressure drop correlation}

For the unsorted and sieved SOPs, a total number of 370 experimental data points for the modified friction factor were collected for the modified $R e$ number ranging from 500 to 12000 , as presented in Fig. 9. This range of modified Re number covers all the flow regimes from laminar to turbulent. In general, the data points collapse on a single curve regardless of the size range. Using the modified Ergun equation, Eq. (14), as the model equation, a correlation for the modified friction factor was obtained by curve fitting, which is expressed as

$$
f_{\mathrm{m}}=213+8.8 \operatorname{Re}_{\mathrm{m}}^{0.87}
$$


with $R^{2}=0.989$. Almost all of the data points lie in the $\pm 10 \%$ range of this correlation. As shown in Fig. 9, it is interesting that the present correlation is in agreement with that proposed by Allen et al. (2013) for the pressure drop through rock beds, which is given by

$$
f_{\mathrm{m}}=200+8 R e_{\mathrm{m}}^{0.88}
$$

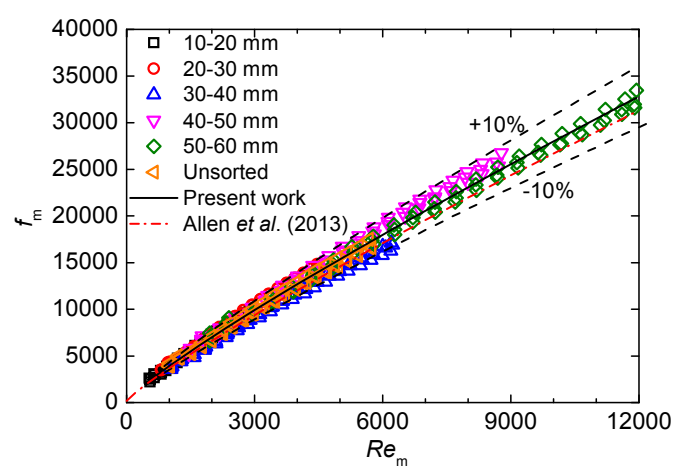

Fig. 9 Measured modified friction factor as a function of the modified $R e$ number for the packed bed with SOPs of various sizes (the variation predicted by an empirical equation proposed by Allen et al. (2013) is given for comparison)

To further verify the utilization of the proposed correlation, SOPs with three particular combinations of size distributions by mass fraction were measured for the same range of superficial velocity from 0.4 to $2.4 \mathrm{~m} / \mathrm{s}$. The prescribed size distributions are specified in Table 7, where the measured geometric properties of these SOP systems with artificial size distributions are also given. Note that the equivalent particle diameters were determined as the weighted average values. The measured pressure drop per unit length as a function of the superficial velocity is plotted in Fig. 10. As expected, the comparison among these SOP systems is consistent with the bed voidage variation. The predicted variations by the proposed correlation, Eq. (17), are also presented in Fig. 10. Obviously, the predicted variation is in good agreement with the measured data for each case. The discrepancy becomes slightly more remarkable at

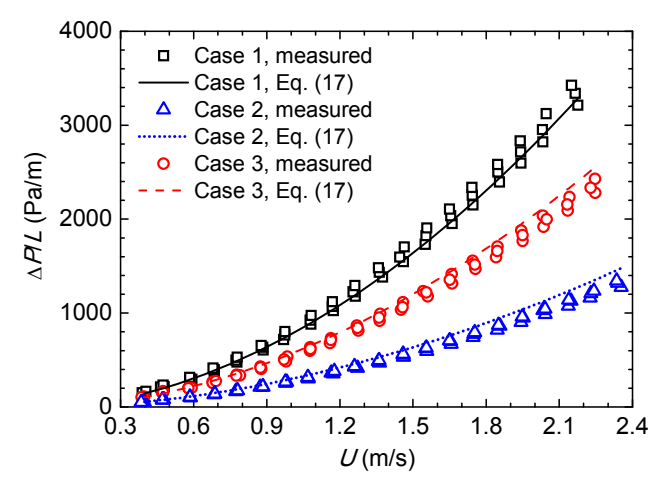

Fig. 10 Comparison between the measured and predicted pressure drops as functions of the superficial velocity for three cases of SOPs with different prescribed size distributions by mass fraction

higher superficial velocities, with the relative deviation being less than $10 \%$. The applicability of the proposed equation is thus well verified for a wide range of flow velocity.

\section{Conclusions}

The pressure drop over a packed bed with SOPs was studied experimentally with application to vertically arranged sinter coolers for waste heat recovery in the iron and steel industry. The tests were performed on a scaled-down test setup for SOPs with various size distributions that were sampled from a product line. Some concluding remarks could be listed as follows:

1. The original Ergun equation fails to predict the pressure drop over the packed bed with such highly irregularly shaped SOPs, with the underestimation by the Ergun equation being found to be about $40 \%$.

2. The modified friction factor fits well to a scaled Ergun equation: $f_{\mathrm{m}}=213+8.8 R e_{\mathrm{m}}^{0.87}$, which is valid for modified $R e$ numbers ranging from 500 to 12000 .

3. By neglecting the wall effect, the pressure drop correlation could be used for the design and

Table 7 Measured geometric properties of the SOPs with prescribed size distributions by mass fraction for model validation

\begin{tabular}{cccccc}
\hline Case & Size $(\mathrm{mm})$ & $d_{\mathrm{p}}(\mathrm{mm})$ & $\varepsilon$ & $\phi$ & $D / d_{\mathrm{p}}$ \\
\hline 1 & $10-20(50 \%), 30-40(50 \%)$ & $13.13 \pm 4.70$ & $0.562 \pm 0.004$ & $0.6383 \pm 0.0612$ & 20.57 \\
2 & $30-40(30 \%), 40-50(30 \%), 50-60(40 \%)$ & $24.06 \pm 5.98$ & $0.595 \pm 0.004$ & $0.6348 \pm 0.0554$ & 11.22 \\
3 & Equally-weighted for $10-60$ & $16.81 \pm 7.75$ & $0.566 \pm 0.004$ & $0.6384 \pm 0.0515$ & 16.06 \\
\hline
\end{tabular}


optimization of vertically arranged sinter coolers with variable structural parameters other than the given values in this study. The wall effect was not addressed quantitatively due to the limitation of the present test setup, and this will be of great interest in future studies.

\section{Acknowledgments}

The authors thank Zhi-yuan WANG, Fen-lei YANG, and Hai-dong WANG from the Hangzhou Iron \& Steel Group Company, China for their assistance in obtaining the sintered ore particles.

\section{References}

Allen, K.G., Backström, T.W., Kröger, D.G., 2013. Packed bed pressure drop dependence on particle shape, size distribution, packing arrangement and roughness. Powder Technology, 246:590-600. http://dx.doi.org/10.1016/j.powtec.2013.06.022

Caputo, A.P., Pelagagge, P.M., 2001. Economic design criteria for cooling solid beds. Applied Thermal Engineering, 21(12):1219-1230. http://dx.doi.org/10.1016/S1359-4311(01)00012-6

Carman, P.C., 1937. Fluid flow through granular beds. Transactions of the Institution of Chemical Engineers, 15:150-166. http://dx.doi.org/10.1016/S0263-8762(97)80003-2

Dong, H., Li, L., Cai, J.J., et al., 2012a. Numerical simulation of heat exchange in vertical tank of waste heat recovery. Journal of Northeastern University (Natural Science), 33(9):1299-1302 (in Chinese).

Dong, H., Li, L., Liu, W.J., et al., 2012b. Process of waste heat recovery and utilization for sinter in vertical tank. China Metallurgy, 22(1):6-11 (in Chinese). http://dx.doi.org/10. 13228/j.boyuan.issn1006-9356.2012.01.009

Dong, H., Feng, J.S., Li, L., et al., 2014. Experimental study on exergy transfer coefficient affected by cooling air volume in vertical tank of waste heat recovery. Journal of Northeastern University, Natural Science, 35(5):708-711 (in Chinese).

Dong, S.F., Li, Y.T., 2011. Study of heat transfer in vertical sinter cooler. Proceedings of the International Conference on Computer Distributed Control and Intelligent Environmental Monitoring, Changsha, China, p.1343-1345. http://dx.doi.org/10.1109/CDCIEM.2011.101

Dukhan, N., Bağcı, Ö., Özdemir, M., 2014. Experimental flow in various porous media and reconciliation of Forchheimer and Ergun relations. Experimental Thermal and Fluid Science, 57:425-433. http://dx.doi.org/10.1016/j.expthermflusci.2014.06.011

Dybbs, A., Edwards, R.V., 1984. A new look at porous media fluid mechanics-Darcy to turbulent. In: Bear, J., Corapcioglu, M.Y. (Eds.), Fundamentals of Transport Phenomena in Porous Media. Springer Netherlands, the
Netherlands, p.199-256.

http://dx.doi.org/10.1007/978-94-009-6175-3_4

Ergun, S., 1952. Fluid flow through packed columns. Chemical Engineering Progress, 48(2):89-94.

Fand, R.M., Kim, B.Y.K., Lam, A.C.C., et al., 1987. Resistance to the flow of fluids through simple and complex porous media whose matrices are composed of randomly packed spheres. Journal of Fluids Engineering, 109(3):268-274.

http://dx.doi.org/10.1115/1.3242658

Feng, J.S., Dong, H., Li, M.M., et al., 2014. Resistance characteristics of fixed bed layer in vertical tank for recovering sinter waste heat. Journal of Central South University, Science and Technology, 45(8):2566-2571 (in Chinese).

Handley, D., Heggs, P.J., 1968. Momentum and heat transfer mechanisms in regular shaped packings. Transactions of the Institution of Chemical Engineers, 46(9):251-264.

Huang, L.F., Tian, F.Y., Li, Q., et al., 2015. Analysis of gas-solid heat transfer performance in vertically-arranged sinter coolers. Journal of Zhejiang University (Engineering Science), 49(5):916-923 (in Chinese).

Jones, D.P., Krier, H., 1983. Gas flow resistance measurements through packed beds at high Reynolds numbers. Journal of Fluids Engineering, 105(2):168-173. http://dx.doi.org/10.1115/1.3240959

Kececioglu, I., Jiang, Y., 1994. Flow through porous media of packed spheres saturated with water. Journal of Fluids Engineering, 116(1):164-170. http://dx.doi.org/10.1115/1.2910229

Leong, J.C., Jin, K.W., Shiau, J.S., et al., 2009. Effect of sinter layer porosity distribution on flow and temperature fields in a sinter cooler. International Journal of Minerals, Metallurgy and Materials, 16(3):265-272.

http://dx.doi.org/10.1016/S1674-4799(09)60048-0

Li, Z., Wu, D., 2007. Effects of finishing rolling temperatures and reduction on the mechanical properties of hot rolled multiphase steel. Journal of Zhejiang UniversitySCIENCE A, 8(5):797-804. http://dx.doi.org/10.1631/jzus.2007.A0797

Liu, Y., Yang, J., Wang, J., et al., 2014. Energy and exergy analysis for waste heat cascade utilization in sinter cooling bed. Energy, 67:370-380. http://dx.doi.org/10.1016/j.energy.2013.11.086

MacDonald, I.F., El-Sayed, M.S., Mow, K., et al., 1979. Flow through porous media - the Ergun's equation revisited. Industrial and Engineering Chemistry Fundamentals, 18(3):199-208. http://dx.doi.org/10.1021/i160071a001

Mayerhofer, M., Govaerts, J., Parmentier, N., et al., 2011. Experimental investigation of pressure drop in packed beds of irregular shaped wood particles. Powder Technology, 205(1-3):30-35. http://dx.doi.org/10.1016/j.powtec.2010.08.006 
Montillet, A., 2004. Flow through a finite packed bed of spheres: a note on the limit of applicability of the Forchheimer-type equation. Journal of Fluids Engineering, 126(1):139-143. http://dx.doi.org/10.1115/1.1637928

Nemec, D., Levec, J., 2005. Flow through packed bed reactors: 1. Single-phase flow. Chemical Engineering Science, 60(24):6947-6957. http://dx.doi.org/10.1016/j.ces.2005.05.068

Pardo, N., Moya, J.A., Vatopoulos, K., 2012. Prospective Scenarios on Energy Efficiency and $\mathrm{CO}_{2}$ Emissions in the EU Iron \& Steel Industry. JRC74811, Institute for Energy and Transport, Joint Research Centre, European Commission, Luxembourg.

Seguin, D., Montillet, A., Comiti, J., et al., 1998. Experimental characterization of flow regimes in various porous media-II: transition to turbulent regime. Chemical Engineering Science, 53(22):3897-3909. http://dx.doi.org/10.1016/S0009-2509(98)80003-1

Shitzer, A., Levy, M., 1983. Transient behaviour of a rock-bed thermal storage system subjected to variable inlet air temperature: analysis and experimentation. Journal of Solar Energy Engineering, 105(2):200-206. http://dx.doi.org/10.1115/1.3266366

Tadayuki, M., Yujiro, S., Kimio, H., et al., 1990. Heat transfer and fluid analysis of sinter coolers with consideration of size segregation and initial temperature distribution. Heat Transfer-Japanese Research, 19(6):537-555.

Tallmadge, J.A., 1970. Packed bed pressure drop-an extension to higher Reynolds numbers. AIChE Journal, 16(6):1092-1093. http://dx.doi.org/10.1002/aic.690160639

Worrell, E., Blinde, P., Neelis, M., et al., 2010. Energy Efficiency Improvement and Cost Saving Opportunities for the U.S. Iron and Steel Industry. LBNL-Report No. 4779E. Ernest Orlando Lawrence Berkeley National Laboratory, University of California, Berkeley, USA.

Wu, W.F., Long, X.P., Yu, X.L., et al., 2012. A new power generation method utilizing a low grade heat source. Journal of Zhejiang University-SCIENCE A (Applied Physics \& Engineering), 13(2):140-145. http://dx.doi.org/10.1631/jzus.A1100152

Yang, S.C. (Ed.), 2014. The Blue Book on the Development of Industrial Energy Conservation and Emission Reduction in China (2013-2014). People Press, Beijing, China, p.93-100 (in Chinese).

Zhang, P.G., Cai, J.J., Dong, H., et al., 2012. Measurement of voidage of sinter ores in the tubes. Industrial and Engineering Chemistry Research, 51(30):10165-10171. http://dx.doi.org/10.1021/ie300801e

Zhang, X.H., Chen, Z., Zhang, J.Y., et al., 2013. Simulation and optimization of waste heat recovery in sinter cooling process. Applied Thermal Engineering, 54(1):7-15. http://dx.doi.org/10.1016/j.applthermaleng.2013.01.017

Zhao, B., Zhang, Y.Z., Cang, D.Q., et al., 2009. Development of a vertical sinter cooler and waste heat generating process. Sintering and Pelletizing, 34(6):5-10 (in Chinese). http://dx.doi.org/10.13403/j.sjqt.2009.06.004

\section{中文概要}

题 目: 应用于余热回收的新型烧结矿立式冷却装置填充 床阻力研究

目 的：研究余热回收中的新型烧结矿立式冷却装置填充 床的阻力特性, 揭示烧结矿填充床宏观特性参数 和空隙流动状态, 提出适用于烧结矿的阻力特性 公式。

创新点：1. 采用实验方法, 获取全面的复杂异形烧结矿颗 粒宏观特性数据; 2. 通过实验测量, 提出适用于 烧结矿填充床的修正型 Ergun 阻力方程。

方 法: 1. 采用多种实验方法, 测量烧结矿的颗粒粒度、 球形度和堆积空隙率等宏观特性参数; 2. 通过阻 力实验数据分析, 得到烧结矿填充床的宏观特性 参数和堆积空隙流动状态; 3 . 通过实验数据拟 合, 提出适用于烧结矿的阻力特性公式。

结 论: 1 . 表观流速为 $0.4-2.4 \mathrm{~m} / \mathrm{s}$ 时烧结矿填充床堆积空 隙流动状态由层流过渡到湍流；2. Ergun 方程的 不规则异形颗粒的阻力预测值比实验值偏低约 $40 \%$ ；3. 提出的修正型 Ergun 预测公式能够预测 颗粒雷诺数 500 至 12000 的烧结矿填充床阻力, 预测误差在 $10 \%$ 以内。

关键词：压降; 多孔介质; 烧结矿冷却; 填充床; 余热 回收 